\title{
Identification of Behaviour Laws and Failure Criteria Parameters of Composites Based on Off Axes Tests Application : Composite Polyester/Alfa
}

\author{
Hichem Smaoui $^{1,2}$, Moez Chafra', Ali Moussaoui ${ }^{1,2}$ and Yvon Chevalier ${ }^{3}$ \\ 'URMCS, ENIT-LASMAP, Ecole Polytechnique of Tunisia \\ e-mail : chafra moez(ayahoo.fr \\ ${ }^{2}$ Laboratory of Biometric Materials and $3 D$ image-making, Kassab Instiute, Tunisia \\ ${ }^{3}$ Laboratory of Engineering of Mechanical Systems and Materials (LEMSMA) \\ Institute Superior of Mechanics of Paris (ISMEP)- Vibroacoustic Group \\ - 3,rue F. Hainaut- 93407 SAINT OUEN cedex (France) \\ e-mail : Yvon.Chevalier(asupmeca.fr
}

\begin{abstract}
The purpose of the present study is to propose a method for identifying the mechanical behaviour of composite materials based on off axes tests for various directions, in a more general framework including a large range of geometrical variables used in industry. We propose a mechanism based mode which strongly depends on the structural anisotropy of the material and on the orientation of loading. For failure we use a quadratic surface similar to Hill criterion, the coefficients of which depend on the type and the direction of loading.

The proposed identification method is applied to a composite made out of woven vegetal fibres and a polyester resin matrix. The fibres are extracted from Alfa leaves which are abundant in North Africa, and are commonly used in the manufacturing of high quality paper.
\end{abstract}

Key Words: Composite, vegetal fibres, Behaviour law, Directional effects, Failure.

\section{INTRODUCTION}

Composites are new materials that have appeared recently and are, generally, composed of two phases: The fibres that are dispersed into another material called the matrix. The composites perform better mechanically than each phase on its own. The research of high technical performances has led to the development of composites which are heterogeneous structures, highly anisotropic due to the arrangement of the phases. This anisotropy has two principal consequences; one is favourable: the possibility of making the fibres in the direction of high stress. The second is unfavourable: the complexity of the modes of possible fracture. The orientation causing this anisotropy must be considered in the modelling of the mechanical behaviour.

During the last twenty years, composite materials have been the subject of a great deal of literature dealing with the analysis and the prediction of their mechanical behaviour. Homogenization in elasticity, which is a classical example, makes it possible to deal with the most complex fiber arrangements, like woven composites $/ 8 /$ in the linear domain, and in the non linear domain $75 /$. In $/ 6,7 /$ the damage is taken into account and computed, whereas the failure analysis by fatigue based criteria, has been developed for instance by Hashin and Rotem /9/. These different approaches include the directional effects, but the composite materials are equally sensitive to the loading nature and modes, as has been shown by Chevalier $e$ al. $/ 4 /$ It is in the nature of composites to exhibit sensitivity with respect to loading mode. This paper presents a threedimensional model of mechanical behaviour and failure 
in composite materials. The model relies on results of off-axes tests performed on samples for various orientations. Our theory takes into account the features of loading (type and direction). To interpret the experimental issues, we constructed a three dimensional model that deals with the composites in linear elasticity, non linear elasticity and plasticity at the macro and meso level referring to the loading characteristics and the mechanical behaviour. Recently we have been dealing with composites reinforced in several directions having one or multi directions, such as the case of woven composites as taffetas. This material belongs to the family of long fibres which has an important place in construction of high mechanical performance structures (aero spatial, aeronautic, automobile, biomechanics, etc.). The objective of this work is to present a modelling of the behaviour of composites in many forms and any mode of reinforcement met in the industry.

An identification procedure has been performed on a composite made out of woven vegetal fibres and a polyester resin matrix. The fibres are extracted from Alfa leaves which are abundant in North Africa. Alfa is an extremely abundant vegetation in Tunisia, especially in the western centre where it covers wide surfaces. It is, essentially, used in paper manufacturing (the Kasserine cellulose factory) which is an important industry in the country ( $3 \%$ of exported products). The idea of manufacturing this composite arose from the abundance and low cost of these natural vegetal fibres, which make them competitive with respect to glass or carbon fibres.

\section{MODELLING OF ELASTIC BEHAVIOUR}

In this part, we propose a three dimensional model for the elastic behaviour. We propose a theoretical study that considers the features of the loading (type and direction) and the non-linear èlastic behaviour of composites. The incremental form of deformation and stress allows the step by step calculation for any loading that is also divided into increments.

To take into consideration the main effects in a composite material, we introduce the following 6dimensional vectorial spaces (Chafra et al., 2002):
- Stress space $(\Sigma)$ spanned by elements of the basis of vectors defined by :

$$
\left\{\Sigma_{\alpha}\right\}=\left\{\begin{array}{l}
\Sigma_{1}=\sigma_{11}, \bar{\Sigma}_{2}=\sigma_{22}, \bar{\Sigma}_{3}=\sqrt{2} \sigma_{12}, \\
\Sigma_{4}=\sigma_{33}, \bar{z}_{5}=\sqrt{2} \sigma_{13}, \Sigma_{6}=\sqrt{2} \sigma_{23}
\end{array}\right\}^{\mathrm{T}}
$$

where $\sigma_{\mathrm{ij}}(\mathrm{i}, \mathrm{j}=1,2,3)$ are the components of the stress tensor

- Strain space ( $E$ ) spanned by elements of the basis of vectors defined by :

$\left\{E_{\alpha}\right\}=\left\{\begin{array}{l}E_{1}-\varepsilon_{11}, E_{2}=\varepsilon_{22}, E_{3}-\sqrt{2} \varepsilon_{12}, \\ E_{4}=\varepsilon_{33}, E_{5}=\sqrt{2} \varepsilon_{13}, E_{6}=\sqrt{2} \varepsilon_{23}\end{array}\right\}^{\mathrm{T}}$

where $\varepsilon_{i j}(i, j=1,2,3)$ are the components of the strain tensor.

We introduce two tensorial invariants, the stress intensity $\Sigma_{0}=\sqrt{\Sigma_{\alpha} \Sigma_{\alpha}}$ and the strain intensity $\mathcal{E}_{0}=\sqrt{\mathscr{E}_{\alpha} \mathcal{E}_{\alpha}}$, deduced from the second order stress and strain tensor.

To study the unilateral effects, we propose to characterize the loading in direction and type:

The loading direction $\theta$ is defined by a unit vector $\left\{\sigma_{\alpha}^{G}\right\} \in\{\Sigma\}$, with $\sqrt{\sigma_{\alpha}^{\theta} \sigma_{\alpha}^{\theta}}=1$ and $\Sigma_{\alpha}=\Sigma_{0} \sigma_{\alpha}^{\theta}$.

The type of loading is defined as a function of the sign configuration of the stress tensor, hence the stress space is decomposed into zones characterized by the sign attributed to each component of stress. For that purpose we define a parameter ( . which corresponds to the number of rows in the sign matrix $[\mathrm{I} \chi a]$ and is equal to the line:

$\left\{\operatorname{sign}\left(\sigma_{1}\right), \operatorname{sign}\left(\sigma_{2}\right), \ldots, \operatorname{sign}\left(\sigma_{6}\right)\right\}$

with sign $\left(\sigma_{\alpha}\right)=\left\{\begin{array}{ccc}1 & \text { if } & \sigma_{\alpha}>0 \\ -1 & \text { if } & \sigma_{\alpha}<0\end{array}\right.$

We consider all the combinations of signs in the stress tensor, therefore the sign matrix is composed of $2^{6}$ 
rows : $\left(\alpha=1,2, \ldots . .6 ; \chi=1,2, \ldots .2^{6}\right)$

$$
\left[\begin{array}{lll}
1_{\chi \alpha} &
\end{array}\right]=\left[\begin{array}{cccccc}
1 & 1 & 1 & 1 & 1 & 1 \\
1 & 1 & 1 & 1 & 1 & -1 \\
1 & 1 & 1 & 1 & -1 & -1 \\
- & - & - & - & - & - \\
- & - & - & - & - & -
\end{array}\right]
$$

In the one dimensional case, the parameter $(\chi)$ is equal to 1 or 2 . We have two spaces with differences in behaviour, and recognize the theory of Ladeveze $17 /$. These differences in behaviour are due to cases of closing (in compression) and opening (in traction) of micro-cracks. When $\alpha,(\alpha \leq 6)$ is the dimension of the subspace of stresses $\left(\chi=1,2, \ldots, 2^{\alpha}\right)$ we have $2^{\alpha}$ zones of loading with different behaviours.

A sign convention is adopted according to the following rules: a positive sign is taken for the tensile stress and a negative sign is taken for the compressive stress. For the shearing stress, we consider the stress vector $\mathbf{T}$ belonging to the shear plane and corresponding to the surface element $\mathbf{n d S}(\mathbf{T}=[\sigma] \mathbf{n})$. Sign (shear stress) $=\operatorname{sign}(\mathbf{N} . T . \operatorname{tg} \varphi$ ), where $\mathrm{N}$ is the projection of the normal vector $\mathbf{n}$ on the shear plane and $\varphi$ the polar angle of $\mathbf{N}$ (see also Chevalier et al. 1998/4/).

During a proportional loading, $\left\{\sigma_{\alpha}=\mathrm{cst}\right\}$, we define a generalized modulus which relates a stress intensity to a strain intensity

$$
\Sigma_{0}=\mathbf{E}(\chi)^{\prime} \mathcal{E}_{0} .
$$

We associate to each type of loading, a Hookean operator $\mathrm{C}$ and its inverse $\mathrm{S}$ such that

$$
\Sigma_{\alpha}=\mathrm{C}_{\alpha \beta}^{(\chi)} \mathcal{E}_{\beta} \text { or } \mathcal{E}_{\underline{\alpha}}=\mathrm{S}_{\alpha \beta}^{(\chi)} \Sigma_{\beta}
$$

In the case of non proportional loading, the constitutive law is defined as an incremental linear elastic law :

$$
\Delta \Sigma_{\alpha}(\mathrm{i})=\mathrm{C}_{\alpha \beta}^{(\chi)} \Delta E_{\beta}(\mathrm{i})
$$

or

$$
\Delta \mathcal{E}_{\alpha}(\mathrm{i})=\mathrm{S}_{\alpha \beta}^{(\chi)} \Delta \Sigma_{\beta}(\mathrm{i})
$$

To describe the variation of elastic compliance in the linear domain which depends on the type and the direction of loading, we construct an iso-strain quadratic surface in the space of stress:

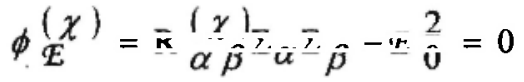

$$
\begin{aligned}
& \left(E_{0}=\text { constant, } \alpha, \beta=1,2,3, \ldots, 6\right)
\end{aligned}
$$

Where $\mathrm{R}_{\alpha \beta}^{(\chi)}$ is related to the components of the compliance matrix :

$$
\mathrm{R}_{\alpha \beta}^{(\chi)}=s_{\alpha \gamma}(\chi)_{\gamma \beta}(\chi)
$$

and is related to the generalized modulus:

$$
\mathbf{E}^{(\chi)}=\frac{1}{\sqrt{\mathrm{R}_{\alpha \beta}^{(\chi)} \sigma_{\alpha^{(r} \beta}}}\left(\left\{\sigma_{\alpha}\right\}=\text { constant }\right)
$$

Chafra 1994 /2/ has given details on the identification of this process.

It can be shown (Chafra et al., $1996 / 3 /$ ), that the matrix $\left[R_{\alpha \beta}\right]$ is non negative and the generalized modulus $\overline{\mathbf{E}}^{\left(n^{\prime}\right)}$ exists.

\section{a- Case of biaxial loading}

In the of biaxial loading the matrix $\left[I_{\chi \alpha}\right]$ is defined by

$$
\left[I_{\chi \alpha}\right]=\left[\begin{array}{cc}
1 & 1 \\
-1 & 1 \\
-1 & -1 \\
1 & -1
\end{array}\right]
$$

$(\alpha=1,2)$ we have four spaces with differences in behaviour $(\chi=1,2,3,4)$.

The constitutive law :

$$
\left\{\begin{array}{l}
\Delta E_{1}=S_{i 1}^{(\tilde{\nu})} \Delta \Sigma_{1}+S_{12}^{(\chi)} \Delta \Sigma_{2} \\
\Delta E_{2}=S_{21}^{(\chi)} \Delta \Sigma_{1}+S_{2 \tilde{2}}^{(\tilde{\nu})} \Delta \Sigma_{2}
\end{array}\right.
$$


with $s_{21}^{(\chi)}=s_{12}^{(\chi)}$

And the isostrain criteria is written as follows:

$$
\mathfrak{R}_{11}^{\left(\chi \chi \Sigma_{1}^{2}\right.}+2 \Re_{12}^{(\chi \chi} \Sigma_{1} \Sigma_{2}+\Re_{22}^{(\chi \gamma} \Sigma_{2}^{2}-\mathrm{E}_{0}^{2}=0
$$

The three parameters that define the quadratic equations (8) are determined uniquely from three experimental points or from more points using a least square method.

\section{Identification procedure:}

- From 3 angles of cutting $\left(0^{\circ}, 45^{\circ}\right.$ and $\left.90^{\circ}\right)$

In the case of biaxial loading we obtain the following relation between $\Sigma_{1}$ and $\Sigma_{2}$

$$
\begin{aligned}
& \left\{\sum_{2}=\mathrm{K}_{\mathrm{a}} \sum_{1}, \mathrm{~K}_{\mathrm{a}}=\operatorname{tg} \alpha\right. \\
& \sum_{1}=\mathrm{K}_{\mathrm{a}} \Sigma_{1}, \mathrm{~K}_{\mathrm{a}}=\operatorname{tg} \alpha \\
& \Rightarrow \\
& \sigma_{1}=\frac{1}{\sqrt{1+K_{a}^{2}}}=\frac{K_{b}^{2}}{\sqrt{1+K_{b}^{2}}} \\
& \sigma_{2}=\frac{1}{\sqrt{1+K_{b}^{2}}}=\frac{K_{\tilde{z}}^{\hat{2}}}{\sqrt{1+K_{a}^{2}}}
\end{aligned}
$$

The isostrain criteria can be written as follows:

$$
\begin{gathered}
\mathfrak{R}_{11}^{(\chi)} \sigma_{1}^{?}+2 \mathfrak{R}_{12}^{\left(\lambda^{\prime}\right)} \sigma_{1} \sigma_{2}+\mathfrak{R}_{22}^{(\chi)} \sigma_{2}^{2}=E_{0}^{2} \\
\Rightarrow \mathfrak{R}_{11}^{(\chi)} \frac{1}{1+K_{a}^{2}} 2 \mathfrak{M}_{12}(\chi) \frac{K_{a}}{1+K_{a}^{2}} \mathfrak{\Re}_{22}(\chi) \frac{K_{a}^{2}}{1+K_{a}^{2}}= \\
=\frac{E_{0}^{2}}{\bar{\Sigma}_{0}^{2}(\alpha)}=\left[S^{\prime}(\chi)(\alpha)\right]^{2}
\end{gathered}
$$

with: $\bar{\Sigma}_{0}(\varphi)=\sqrt{\Sigma_{1}^{2}+\bar{\Sigma}^{\frac{2}{2}}}$ and $\left[S^{\prime}(\chi)(\alpha)\right]=\frac{E_{0}}{\bar{\Sigma}_{0}(\alpha)}$

if $\alpha=0^{\circ} \Rightarrow K_{a}=0$ and $\mathfrak{R}_{11}^{(\chi)}=\left[S^{(\chi)}\left(0^{\circ}\right)\right]^{2}$

if $\alpha .=90^{\circ} \Rightarrow K_{g} \rightarrow 0$ and $\mathfrak{R}_{22}^{\left(\tilde{n}^{\prime}\right)}=\left[S^{\prime}(\chi)\left(90^{\circ}\right)\right]^{2}$ if $\alpha=45^{\circ} \Rightarrow K_{a}=1$ and

$\mathfrak{R}_{12}^{(\chi)}=\left[S^{\prime}(\chi)\left(45^{\circ}\right)\right]^{2}-$

$-\frac{1}{2}\left(\left[s^{(\chi)}\left(0^{\circ}\right)\right]^{2}+\left[s^{(x)}\left(90^{\circ}\right)\right]^{2}\right)$

- From the least square method $\left(0^{\circ}, 30^{\circ}, 45^{\circ}, 60^{\circ}\right.$ and $90^{\circ}$ )

$$
\{\mathfrak{R}\}=-\left[A^{T} \cdot A\right]^{-1} \cdot A^{T} \cdot d_{0}
$$

where

$$
\begin{aligned}
& \mathfrak{R}=\left\langle\mathfrak{R}_{11}^{(\chi)} \mathfrak{R}_{12}^{(\chi)} \mathfrak{R}_{22}^{(\chi)}>T\right. \\
& {[A]=\left[\begin{array}{llllll}
P_{1} & P_{2} & P_{3} & P_{4} & P_{5}
\end{array}\right]^{T}} \\
& \left\{P_{i}\right\}=\left\{\begin{array}{llllllll}
\Sigma_{1 i}^{2} \Sigma_{1 i} & \Sigma_{2} & i_{2} \Sigma_{2}^{2}
\end{array}\right\}^{T} \\
& \left\{d_{0}\right\}=E_{0}^{2} \quad\left\{\begin{array}{lllll}
1 & 1 & 1 & 1 & 1
\end{array}\right\}^{T}
\end{aligned}
$$

$\Sigma_{j i}$ stress value for the case $\mathrm{i}$ of cutting $\left(0^{\circ}, 30^{\circ}, 45^{\circ}\right.$, $\left.60^{\circ}, 90^{\circ}\right)$

\section{b- Use of experimental results}

We often use an experimental method using samples out off axes for various directions (Figure 1). The results provided by a test are the longitudinal modulus, while the results used in the models are the generalized modulus.

By means of the transformation method, we establish the following relation between $\Sigma_{1}, \Sigma_{2}$ and $\sigma_{\mathrm{L}}$.

$$
\begin{gathered}
\left\{\begin{array}{c}
\Sigma_{1}=\sigma_{L} \cos ^{2} \theta \\
\Sigma_{2}=\sigma_{L} \sin ^{2} \theta \\
\frac{1}{\sqrt{2}} \Sigma_{3}=-\sigma_{L} \cos \theta \sin \theta
\end{array}\right. \\
\Rightarrow \quad \operatorname{tg} \alpha=\operatorname{tg}^{2} \theta
\end{gathered}
$$

We define the longitudinal modulus and Poisson ratio, and we calculate $\Sigma_{0}$ and $E_{0}$ 


$$
\Sigma_{0}=\sqrt{\Sigma_{1}^{2}+\Sigma_{2}^{2}+\Sigma_{3}^{2}}=\sigma_{L}
$$

and $\mathbf{E}_{L}^{(\chi)}(\theta)=\frac{\sigma_{L}}{\varepsilon_{L}}$

$$
\begin{aligned}
& \mathcal{E}_{0}=\sqrt{\varepsilon_{I}^{2}+\varepsilon_{T}^{2}}=\varepsilon_{L} \sqrt{1+v_{L T}^{2}} \\
& v_{L T}^{(\chi)}(\theta)=-\frac{\varepsilon_{T}}{\varepsilon_{L}}
\end{aligned}
$$

Then $\Sigma_{0}=\bar{\Sigma}_{0} \sqrt{\cos ^{4}(\theta)+\sin ^{4}(\theta)}$ with $\Sigma_{0}=\sqrt{\Sigma_{1}^{2}+\Sigma_{2}^{2}}$ and

$$
\mathbf{E}^{(\chi)}(\theta)=\frac{\Sigma_{0}}{\varepsilon_{0}}=\frac{\sigma_{L}}{\varepsilon_{L} \sqrt{1+v_{L T}^{2}(\theta)}}=\frac{\mathbf{E}_{L}^{(\chi)}(\theta)}{\sqrt{1+v_{L T}^{2}(\theta)}}
$$

We establish the elastic modulus

$$
\mathbf{E}^{(\chi)}(\alpha)=\frac{\bar{\Sigma}_{0}}{\mathcal{E}_{0}}=\frac{\mathbf{E}_{L}^{(\chi)}(\theta) \sqrt{\cos ^{4}(\theta)+\sin ^{4}(\theta)}}{\sqrt{1+v_{L T}^{2}(\theta)}}
$$

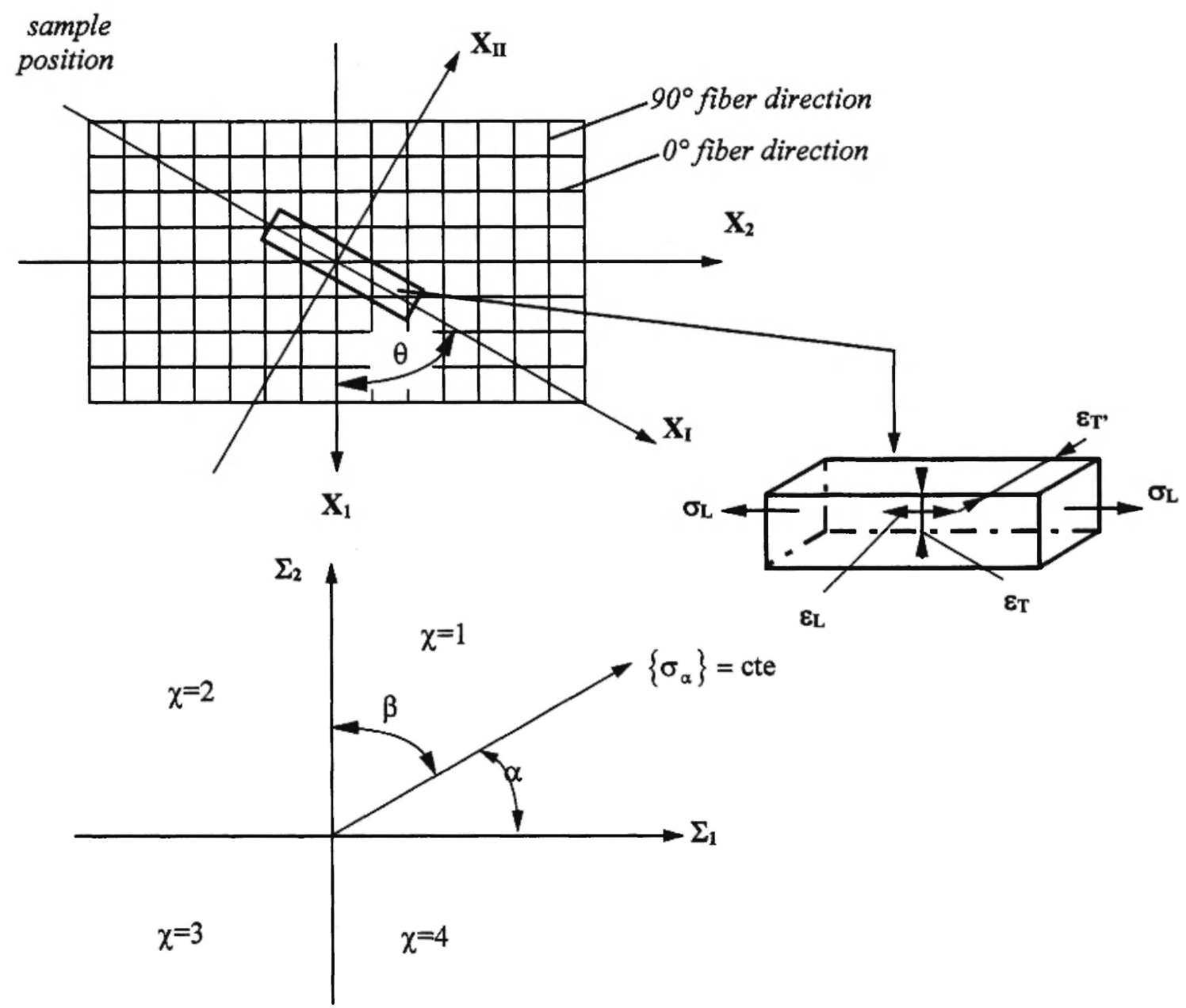

Fig. 1: Off axes tests and loading direction 
With three values of $\mathbf{S}^{\prime(x)}(\alpha)$, for $\alpha=0^{\circ}, 45^{\circ}$ and $90^{\circ}$, we identify the parameters of surface $R_{11}^{(\chi)}, R_{22}^{(x)}$ and $R_{12}^{(\chi)}$ by the relation (9), and following these parameters we express for each the mechanical characteristic for the constitutive law (7).

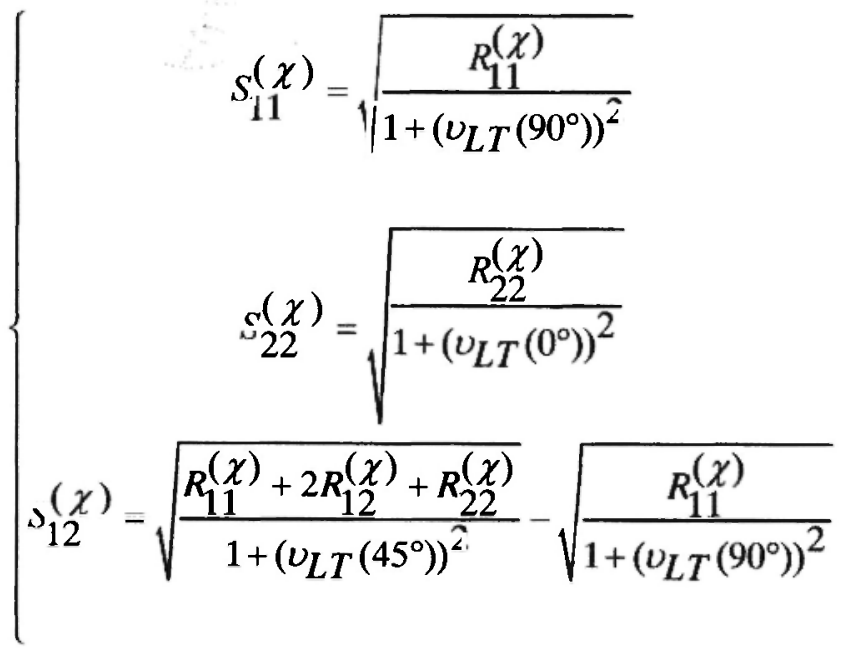

\section{FAILURE CRITERIA}

For failure we have introduced a quadratic surface similar to the Hill criterion

$\mathrm{F}_{\alpha \beta}^{(\chi)} \Sigma_{\alpha} \Sigma_{\beta}=1$

$(\alpha, \beta=1,2, \ldots, 6)$

Coefficients $\mathrm{F}_{\chi \beta}^{(\chi)}$ depend on the type and direction of loading, and are related to the failure limit: $\Sigma_{F}(\alpha)=\frac{1}{\sqrt{F_{\alpha \beta}^{(\chi)} \sigma_{\alpha} \sigma_{\beta}}}$

In the case of biaxial loading $\left(\Sigma_{1}, \Sigma_{2}\right)$ the constitutive law is defined by 3 compliances $\mathrm{s}_{11}(x), \mathrm{s}_{22}(x), \mathrm{s}_{12}(x)$, and the failure criteria is defined by three parameters $\mathrm{F}_{i}(x), \mathrm{F}_{22}^{(\pi)}, \mathrm{F}_{12}(x)$ :

At the failure point, the model is given by the expression:

$$
\begin{aligned}
f_{F}^{(\chi)} & \equiv F_{11}^{(\chi)} \Sigma_{1}^{2}+2 F_{12}^{(\chi)} \Sigma_{1} \Sigma_{2} \\
& +F_{22}^{(\chi)} \Sigma_{2}^{2}-1=0
\end{aligned}
$$

where,

$$
\left\{\begin{array}{c}
F_{11}^{(\chi)}=\frac{1}{\left(\Sigma_{F}\left(0^{\circ}\right)\right)^{2}} \\
F_{22}^{(\chi)}=\frac{1}{\left(\Sigma_{F}\left(90^{\circ}\right)\right)^{2}} \\
F_{12}^{(\chi)}=\frac{1}{\left(\Sigma_{F}\left(45^{\circ}\right)\right)^{2}}-\frac{1}{2}\left[\frac{1}{\left(\Sigma_{F}\left(0^{\circ}\right)\right)^{2}}+\frac{1}{\left(\Sigma_{F}\left(90^{\circ}\right)\right)^{2}}\right]
\end{array}\right\}
$$

$\Sigma_{F}\left(0^{\circ}\right), \quad \Sigma_{F}\left(45^{\circ}\right) \quad$ and $\quad \Sigma_{F}\left(90^{\circ}\right) \quad$ represent respectively the stresses of failure corresponding to $\alpha=0^{\circ}, 45^{\circ}$ and $90^{\circ}$.

By means of the transformation method, we establish the following relation (see Figure 1 and use of experimental results) :

$$
\sigma_{\mathrm{F}}(\theta)=\Sigma_{\mathrm{F}}(\alpha) \sqrt{\cos ^{4}(\theta)+\sin ^{4}(\theta)}
$$

$\sigma_{\mathrm{F}}(\theta)$ is the value of the stress, measured directly from the diagram of stress-strain.

$\theta$ is the angle of cutting.

$\alpha$ is the angle of loading.

$$
\operatorname{tg} \alpha=\operatorname{tg}^{2}(\theta)
$$

\section{MODE OF MANUFACTURING OF THE ALFA/ POLYESTER COMPOSITE}

The tested composite material is made manually, out of long Alfa fibres, woven in taffeta pattern, and a polyester resin.

The manufacturing steps are as follows:

\section{I" stage: Elimination of lignin and hemicelluloses}

These two elements reduce the fibre resistance. They may be eliminated by heating in a solution of sodium hydroxide $(\mathrm{NaOH})$ as follows:

- Introduce, into a glass balloon containing 1 litre of water, $120 \mathrm{~g}$ of $\mathrm{NaOH}$, stir to dissolve the grains of sodium hydroxide, and then add about $60 \mathrm{~g}$ to $70 \mathrm{~g}$ of Alfa. 
- Heat the balloon above $100^{\circ} \mathrm{C}$ for 2 hours.

- Cool the content of the balloon by washing it several times with distilled water.

- Pour into the balloon 1 litre of purified water and 40 $\mathrm{ml}$ of $12^{\circ} \mathrm{s}$ sodium chloride, then leave for one hour to dissolve the $\mathrm{Na}^{+}$ions.

- Wash several times the contents of the balloon with distilled water.

- Dry the content on a paper and then put it into a steamer for 24 hours at a temperature about $40^{\circ} \mathrm{C}$. $\underline{2}^{\text {nd }}$ stage: Refinement of fibres:

The quantity of Alfa removed from the steam is brushed with a hair brush then with a tooth brush to make the fibres as fine as possible.

$3^{\text {rd }}$ stage: Weaving of the textures of Alfa fibres:

Textures are woven by hand in taffeta pattern in two perpendicular and crossed directions.

The parameters of texture are illustrated in the following table:

\begin{tabular}{|c|c|c|c|}
\hline Parameter & Denomination & Definition & Value \\
\hline$n_{1}$ & $\begin{array}{l}\text { parameter of } \\
\text { texture }\end{array}$ & number of threads in a stitch & 2 \\
\hline$\xi=a / 1$ & $\begin{array}{l}\text { factor of } \\
\text { constriction }\end{array}$ & $\begin{array}{l}\text { fraction of the width of a wick to the width of a } \\
\text { stitch }\end{array}$ & 0.33 \\
\hline $\mathrm{V}_{\mathrm{f}}$ & $\begin{array}{l}\text { volume fraction of } \\
\text { fibres }\end{array}$ & fraction of fibres volume to total volume & 0.233 \\
\hline$\eta=\frac{L_{c}-L_{t}}{L_{l}}$ & ambulate & $\begin{array}{l}\text { Relative shortening of chain threads. (Lc length of } \\
\text { the chain thread, } L_{t} \text { length of texture). }\end{array}$ & $4.5 \%$ \\
\hline $\mathrm{R}=\xi(2-\xi)$ & factor of recovery & $\begin{array}{l}\text { Fraction of reinforcement to that cross section } \\
\text { area of the texture }\end{array}$ & 0.55 \\
\hline$\theta=\frac{d}{e}=\frac{V_{f}}{\xi(2-\xi)}$ & factor of stacking & $\begin{array}{l}\text { fraction of thickness of fibre to thickness of stitch } \\
\text { (e) }\end{array}$ & 0.42 \\
\hline $\mathrm{Gr}=\mathrm{R} \mathrm{d} \rho_{f}$ & Surface weight & $\begin{array}{l}\text { weight of texture by square meter. } \rho_{f} \text { is the } \\
\text { specific mass of the fibre. }\end{array}$ & $118,31 \mathrm{gr} / \mathrm{m}^{2}$ \\
\hline
\end{tabular}

\section{$4^{\text {th }}$ stage: Milling of the composite material:}

The milling of the material is done by an a'uminium mold $\left(270 \times 270 \times 30 \mathrm{~mm}^{\prime}\right.$ and $270 \times$ $\left.270 \times 20 \mathrm{~mm}^{3}\right)$. The manufacturing process is summarized in the following steps:

1. Apply and sweep milling off wax over the surface of the mould.

2. Spread of $1^{\text {st }}$ layer of resin in the mould

3. Put the texture in place.

4. Spread $2^{\text {nd }}$ layer of resin

5. Roll tightly to eliminate air

6. Regularize surface with a trowel
7. Dry at room temperature

8. Mill off plate.

9. Cut plate into test samples.

\section{Physical -features of used materials:}

- Average diameter of the fibres: $0,75 \mathrm{mms}$.

- Average spacing of fibres: $1,5 \mathrm{mms}$

-Volume percentage of fibres: $24 \%$

- Specific weight of the fibres: $250 \mathrm{Kg} / \mathrm{m} 3$

- Specific weight of the polyester resin: $1100 \mathrm{Kg} / \mathrm{m} 3$

- Specific weight of the composite: $1150 \mathrm{Kg} / \mathrm{m} 3$ 


\section{Speed of traction test:}

It is the speed of separation of two clamps of the traction machine. It is equal to $2 \mathrm{~mm} / \mathrm{mins}$.

\section{Results of the traction tests:}

The graphic results of traction tests are illustrated by the stress-strain diagrams.

The results of traction tests to the $0^{\circ}$ 's direction are illustrated in the following table:

\begin{tabular}{|c|c|c|c|c|}
\hline $\mathrm{N}^{\circ}$ of plate & $\begin{array}{c}\text { Stress at failure rupture } \\
{[\mathrm{MPa}]}\end{array}$ & $\begin{array}{c}\text { Stress at 0,05\% of strain } \\
{[\mathrm{MPa}]}\end{array}$ & $\begin{array}{c}\text { Stress at 0,25\% of strain } \\
{[\mathrm{MPa}]}\end{array}$ & Strain at failure [\%] \\
\hline P1 & 132 & 6,25 & 20 & 2 \\
\hline P2 & 105 & 3,4 & 16,2 & 1,8 \\
\hline P3 & 108 & 3,2 & 15,2 & 1,8 \\
\hline P4 & 95 & 4,2 & 20,5 & 1,6 \\
\hline P5 & 92 & 3,2 & 16,4 & 2 \\
\hline
\end{tabular}

The results of traction tests to the $45^{\circ}$ 's direction, are illustrated in the following table:

\begin{tabular}{|c|c|c|c|c|}
\hline $\mathrm{N}^{\circ}$ of plate & Stress at failure [MPa ] & $\begin{array}{c}\text { Stress at 0,05\% of strain } \\
{[\mathrm{MPa}]}\end{array}$ & $\begin{array}{c}\text { Stress at } 0,25 \% \text { of } \\
\text { strain[MPa] }\end{array}$ & Strain at failure [\%] \\
\hline P6 & 87 & 4,1 & 14,2 & 1,8 \\
\hline P7 & 70 & 4,5 & 11,5 & 1,2 \\
\hline P8 & 75 & 4,5 & 13,8 & 1,4 \\
\hline
\end{tabular}

The results of traction tests to the $30^{\circ}$ 's direction, are illustrated in the following table:

\begin{tabular}{|c|c|c|c|c|}
\hline $\mathrm{N}^{\circ}$ of plate & Stress at failure [MPa ] & $\begin{array}{c}\text { Stress at 0,05 \% of } \\
\text { strain [MP }\end{array}$ & $\begin{array}{c}\text { Stress at 0,25 \% of } \\
\text { strain[MPa] }\end{array}$ & Strain at failure [\%] \\
\hline P9 & 88 & 4,1 & 15,4 & 1,4 \\
\hline P10 & 80 & 3,7 & 14,6 & 1,4 \\
\hline P11 & 77 & 3,5 & 14,86 & 1,35 \\
\hline
\end{tabular}

\section{Principal mechanical characteristics of the} composite

$E_{l}^{(\chi)}\left(0^{\circ}\right)=E_{L}^{(\chi)}\left(90^{\circ}\right)=6385 \mathrm{MPa} ;$

$E_{L}^{(\chi)}\left(45^{\circ}\right)=4710 \mathrm{MPa}$;

$E_{L}^{(\chi)}\left(30^{\circ}\right)=E_{l}^{(\chi)}\left(60^{\circ}\right)=5594 \mathrm{MPa}$.

$G_{12}=1600 \mathrm{MPa}$;

$G_{13}=2900 \mathrm{MPa}$;

$G_{23}=1400 \mathrm{MPa}$

$v_{\mathrm{IIT}}\left(0^{\circ}\right)=v_{\mathrm{I}, \mathrm{T}}\left(90^{\circ}\right)=0,27$

$v_{\mathrm{LI}}\left(45^{\circ}\right)=0,48$;

$v_{1, T}\left(30^{\circ}\right)=v_{1},\left(60^{\circ}\right)=0,46$

\section{5- VALIDATION OF THE MODEL:}

In this part, we will try to validate the model by using the results of tractions tests on the composite.

\section{a) Elastic domain}

An identification procedure has been performed on woven Alfa/Polyester composite.

Criteria of iso strain's expression :

- From three angles of cutting $\left(0^{\circ}, 45^{\circ}\right.$ and $\left.90^{\circ}\right)$

$$
26,31 \Sigma_{1}^{2}+164,40 \Sigma_{1} \Sigma_{2}+26,31 \Sigma_{2}^{2}-10^{9} F_{\hat{v}}^{2}=0
$$


- From the least square method $\left(0^{\circ}, 30^{\circ}, 45^{\circ}, 60^{\circ}\right.$ and $\left.90^{\circ}\right)$

$$
33,18 \Sigma_{1}^{2}+149,84 \Sigma_{1} \Sigma_{2}+33,18 \Sigma_{2}^{2}-10^{9} \underline{F}_{\hat{v}}^{2}=0
$$

Experimental results concerning this formulation are given in Figures 2, 3 and 4.

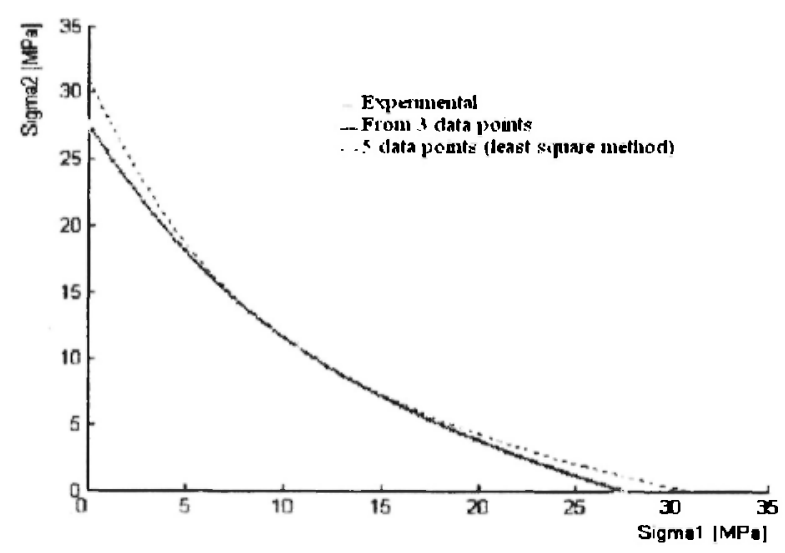

Fig. 2: Isostrain criteria for a woven Alfa/Polyester composite in the linear range $(\chi=1)$. For $\mathrm{E}_{0}=$ $0,5 \%$

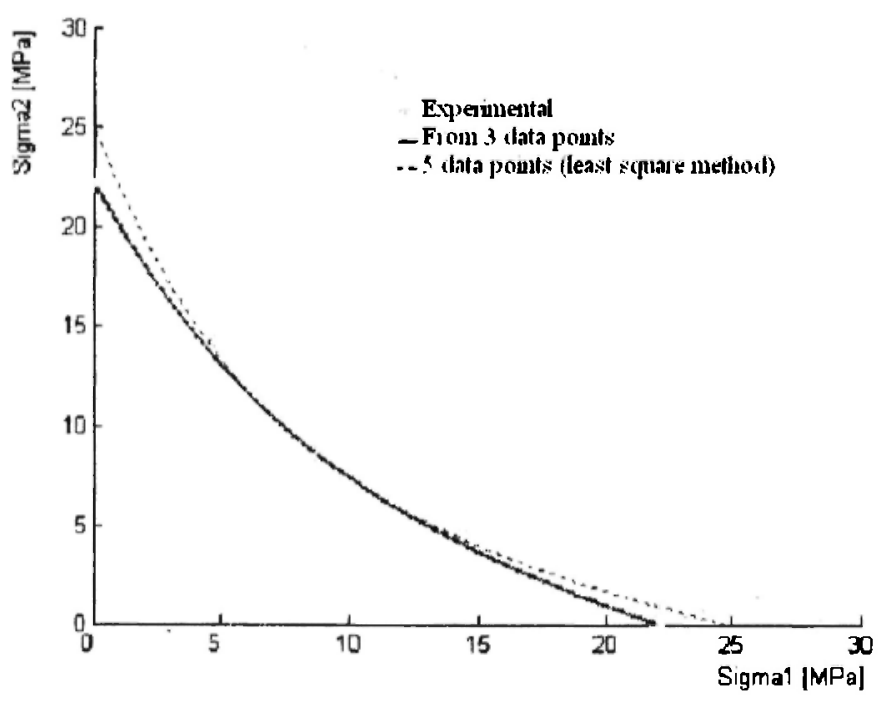

Fig. 3: Isostrain criteria for a woven Alfa/Polyester composite in the linear range $(\chi=1)$. For $\mathrm{E}_{0}=$ $0,4 \%$

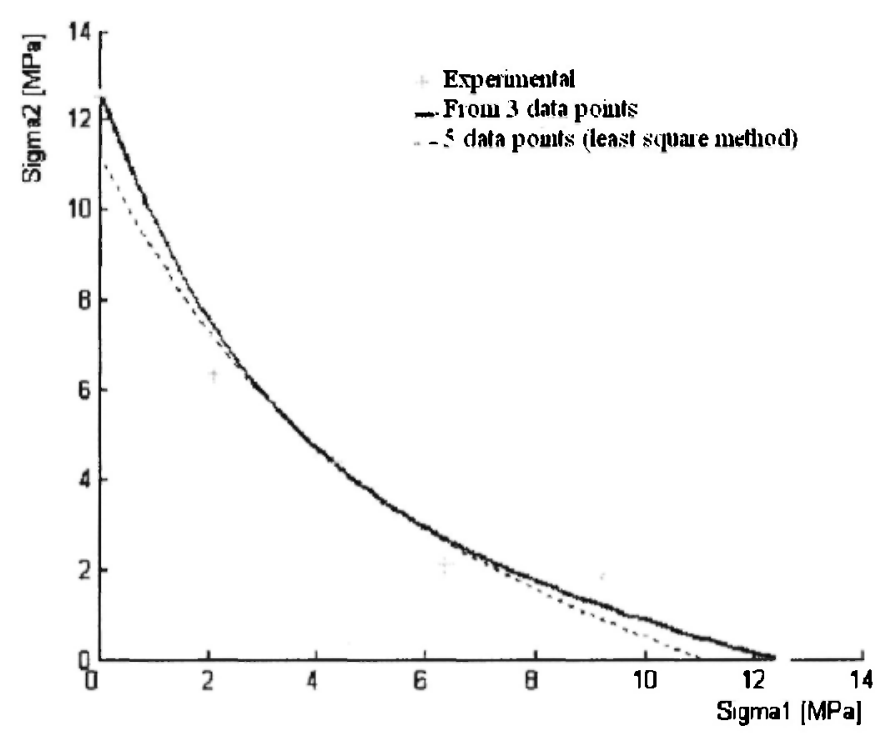

Fig. 4: Isostrain criteria for a woven Alfa/Polyester composite in the linear range $(\chi=1)$. For $\mathrm{E}_{0}=$ $0,2 \%$

Following the iso strain criteria we express the mechanical characteristic for the constitutive law (7):

$$
\left\{\begin{array}{l}
\Sigma_{1} \\
\Sigma_{2}
\end{array}\right\}=\left[\begin{array}{ll}
6386,1 & 1754,5 \\
1754,5 & 6386,1
\end{array}\right]\left\{\begin{array}{l}
E_{1} \\
E_{2}
\end{array}\right\}
$$

\section{b) Case of failure:}

An identification procedure has been performed on woven Alfa/Polyester composite.(Figure 5 and Table 1).

Table 1

Stresses at failure corresponding to $\varphi=0^{\circ}, 45^{\circ}$ and $90^{\circ}$.:

\begin{tabular}{|c|c|c|}
\hline$\theta$ & $\sigma_{F}[M P a]$ & $\Sigma_{F}[M P a]$ \\
\hline $0^{\circ}$ et $90^{\circ}$ & 106,4 & 106,4 \\
\hline $30^{\circ}$ et $60^{\circ}$ & 81,67 & 64,56 \\
\hline $45^{\circ}$ & 77,3 & 54,66 \\
\hline
\end{tabular}

Failure criteria expression :

- From three angles of cutting $\left(0^{\circ}, 45^{\circ}\right.$ and $\left.90^{\circ}\right)$

$$
88,33 \Sigma_{1}^{2}+495,20 \Sigma_{1} \Sigma_{2}+88,33 \Sigma_{2}^{2}=10^{6}
$$


- From the minimum square method $\left(0^{\circ}, 30^{\circ}, 45^{\circ}, 60^{\circ}\right.$ and $90^{\circ}$ )

$$
88,4 \Sigma_{1}^{2}+499 \Sigma_{1} \Sigma_{2}+88,4 \Sigma_{2}^{2}=10^{6}
$$

\section{Graphic representation :}

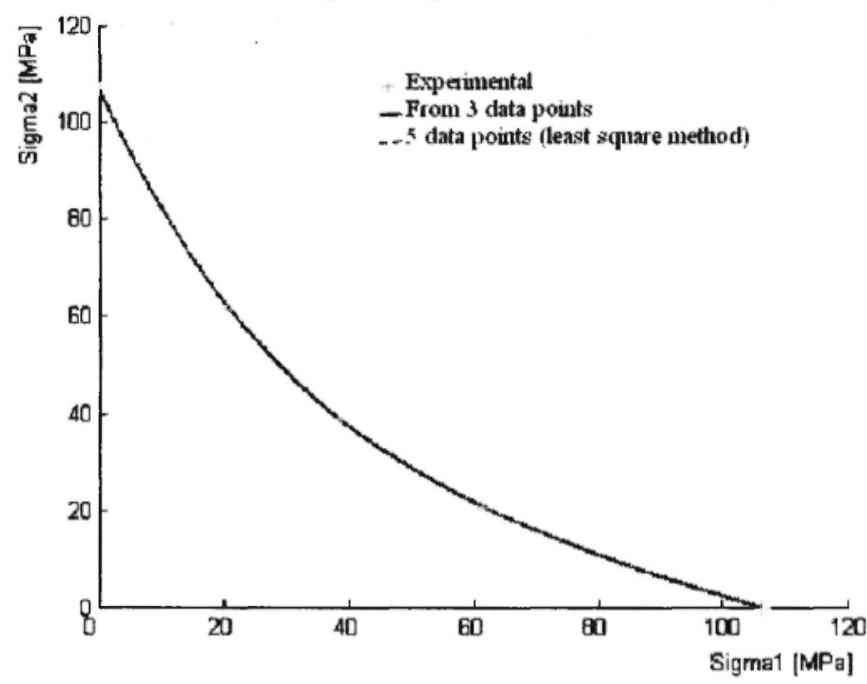

Fig. 5: Failure criteria (zone of loading $(\chi=1)$ ).

\section{CONCLUSION}

In this work, we propose a method for identifying the mechanical behaviour of composite materials based on off-axes tests for various directions. The Hill criterion is adopted with parameters that depend on the type and direction of loading. An identification procedure has been performed on woven Alfa/Polyester composite. The mechanical characteristics of the composite Alfa/Polyester, in any direction, are easily identified.

The use of Alfa fibres is justified by the abundance and low cost of these natural vegetal fibres, which make them competitive with respect to glass or carbon fibres.

\section{REFERENCES}

1. M. Chafra and Y. Chevalier. Damage oriented and failure of composites materials under cycling loading, in: Durability Analysis of Composite Systems, C.. Miyano, K. Reifsnider, D. Dillard, A. Cardon, and C. Ogihara (Eds) 2002.

2. M. Chafra. Comportement mécanique des matériaux composites fibrés et tissés, Modelisation tridimensionnelle - endommagement et rupture. Thèse de doctorat CNAM Paris 1994.

3. M. Chafra, A. Baltov and T. Vinh. Modélisation tridimensionnelle des materiaux composites endommagement et rupture, Revue des Composites et des Materiaux Avancés. 6 (1) 49-72 (1996).

4. Y. Chevalier, M.Louzar, M. Chafra and G.A. Maugin, Damage modelling of composite structures: static and dynamic approach, in: Progress in Durability Analysis of Composite Systems, K. Reifsnider, D. Dillard and A. Cardon, (Eds.), A.A. Balkema/Rotterdam/Brookfield, 1998.

5. T.W. Chou and T. Ishikawa, Non linear behaviour of woven fabric composites. J. Comp.Mat., 17, 399413 (1983).

6. P. Ladeveze, Damage computation method for composite structures. Computer \& Structures, 44, 79-87 (1992).

7. P. Ladeveze, O. Allix and C. Cluzel, Damage modelling at the macro and meso-scales for $3 \mathrm{D}$ composites, in: Damage in Composite Materials, G.Z. Voyiadjis (Ed.), 1993 ; pp.195-215.

8. F. Lené and D. Leguillon D, Etude de l'influence d'un glissement entre les constituants d'un materiau composite sur les coefficients de comportement effectifs, Journal de Mecanique , 20 (3), 509-536 (1981).

9. Z. Hashin, A. Rotem. A fatigue failure criterion for fiber reinforced materials, J. Comp.Mat., 7, 448-465 (1973). 